\title{
EDITORIAL
}

\section{La salud como herramienta fundamental para el desarrollo sostenible}

Darío Chávez'

La salud debe ser vista como una herramienta fundamental para el desarrollo sostenible. El enfoque de la Universidad Evangélica de El Salvador, (UEES), en este sentido es holístico y destaca aspectos físicos, mentales, sociales y espirituales. La salud es retomada desde un paradigma integral que abarca aspectos de promoción de la salud, prevención, curación y rehabilitación de la enfermedad.

El desarrollo se logra fomentando la educación, investigación y tecnología, promoviendo "el derecho y la disposición de participar en una comunidad, a través de la acción autorregulada, inclusiva, democrática, pacífica y responsable, para maximizar el bienestar público" ${ }^{11}$. Por otro lado uno de los desafíos más importantes para los países en desarrollo es una mayor valorización de sus conocimientos locales. $^{2}$

La Universidad Evangélica de El Salvador, considera a la investigación en salud como un impulsor y catalizador del desarrollo humano sostenible, que debería incidir en última instancia en aspectos estructurales que determinan el bienestar individual y social.

Consciente de su papel transformador de la realidad, fomenta la producción y divulgación científica, contando para esto con medios de publicación de estudios de autores internos y externos de nuestra comunidad educativa. La Universidad apuesta a la promoción de una cultura investigativa que esté consciente que las investigaciones que se realizan deben tener impacto y trascendencia, esto solo se puede lograr divulgando los resultados y recomendaciones por medios físicos y electrónicos.

Crea Ciencia, va ganando terreno constituyéndose en una revista de referencia nacional, e internacional siendo editada en español e inglés, representando una oportunidad para los investigadores de publicar sus producciones científicas en un medio que satisface los requerimientos de indexación y arbitraje, permitiendo además otorgar créditos a profesionales en un momento en el que la certificación y recertificación cobra relevancia en nuestro país. 
En este tomo de la revista Crea Ciencia se abordan diversos temas de la salud que responden a necesidades reales locales, regionales o internacionales.

Para su lectura, se cuenta con una copia física y / o electrónica www.uees.edu.sv

\section{Fuentes Consultadas}

1. Tang, Qian, Subdirector General de la UNESCO imparte conferencia magistral en Universidad 2012, disponible en: http://www.unesco.org/new/es/media-services/single view/news/autoridad_ de_la_unesco_imparte_conferencia_magistral_en_congreso_universidad_2012_only_in_spanish/\#. Um1gVHljnIU

2. Jéroneme, Bindé, Hacia las sociedades del conocimiento: Informe Mundial de la UNESCO, 2005, página 100. Disponible en http://unesdoc.unesco.org/ulis/cgi-bin/ulis. $\mathrm{pl}$ ?catno $=141908 \& \mathrm{gp}=1 \& \operatorname{mode}=\mathrm{e} \& \mathrm{lin}=1$ 